\title{
The performance of an urban road system using Data Envelope Analysis
}

\author{
G. Fancello \& B. Uccheddu \& P. Fadda \\ DICAAR Dipartimento Ingegneria Civile, Ambientale ed Architettura, \\ Università di Cagliari, Italy
}

\begin{abstract}
Improving the efficiency of transport networks by enhancing road system performance, lays the foundations for the positive change process within a city, achieving good accessibility to the area and optimizing vehicle flows, both in terms of cost management and attenuation of environmental impacts. The performance of an urban road system can be defined according to different thematic areas such as traffic flow, accessibility, maintenance and safety, for which the scientific literature proposes different measurement indicators. However variations in performance are influenced by interventions which differ from one another, such as infrastructure, management, regulation or legislation, etc. Therefore sometimes it is not easy to understand which areas to act on and what type of action to pursue to improve road network performance. Of particular interest are the tools based on the use of synthetic macro-indicators that are representative of the individual thematic areas and are able to describe the behavior of the entire network as a function of its characteristic elements. These instruments are of major significance when they assess performance not so much in absolute terms but in relative terms, i.e. in relation to other urban areas comparable to the one being examined. Therefore, the objective of the proposed paper is to compare performances of different urban networks, using a nonparametric linear programming technique such as Data Envelopment Analysis (DEA), in order to provide technical support to the policy maker in the choice of actions to be implemented to make the systems efficient urban roads.
\end{abstract}

Keywords: road networks, efficiency, DEA. 


\section{Introduction}

DEA is a typical benchmarking analysis, commonly used in econometrics to estimate the efficiency of production units and for years it has found wide application in areas such as health, education, finance, local public transport, ICT and macroeconomics of sector studies. Only recently this technique has been used in other contexts of the transportation sector.

In this paper it will be applied for the first time to the comparison of urban road systems in different cities. The aim of DEA is to calculate an efficiency frontier measured as relative performance of different units called DMU (Decision Making Unit) in terms of distance per unit to the ideal frontier, constructed using observed input and output data. The efficiency frontier is a set of points that shows the efficient combination of input and output that can be obtained in the systems examined [3]. Figure 1 shows a graphical DEA representation in which three DMU (A, B and C), are compared, each using a single input $\mathrm{x}$ to produce the output $\mathrm{y}$. The line shows the efficiency frontier: point $\mathrm{A}$ on the frontier represents an efficient DMU and the points B and C, outside the frontier, the inefficient DMU [4].

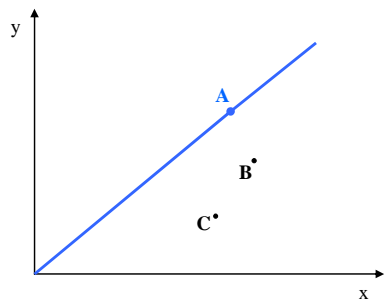

Figure 1: $\quad$ Representation of DEA.

The objective of the proposed paper is to compare performances of different urban networks, using a non-parametric linear programming technique such as Data Envelopment Analysis (DEA) [1], in order to provide technical support to the policy maker in the choice of actions to be implemented to make the systems efficient urban roads. In this investigation, concerning the use of DEA to study the efficiency of roads systems, the DMUs are the road networks for different urban contexts. Inputs and outputs are selected from among the main characteristics of road system indicators: traffic flow, accessibility and safety. The analysis will have an input-oriented approach where, starting from fixed outputs, the optimal value will be defined, in percentage terms, as the amount of input that the road system can cope with to become efficient. The concept of "performance" of an urban transport network will be explored, highlighting what has emerged from analysis of the state-of-the-art literature, with specific reference to synthetic indicators calculation representing different issues. The inputs will be identified by examining the needs that emerged from the analysis of population mobility and accessibility, while the outputs will be defined according to traffic flow states, environmental quality and safety. The 
application, simply illustrative, concerned the urban road networks in eight different cities (Benevento, Caltanissetta, Crotone, Matera, Savona, Viareggio, Vigevano e Viterbo) selected according to the following criteria: population between 60,000 and 65,000 and perimeter of the urban area between $15 \mathrm{~km}$ and $20 \mathrm{~km}$. DEA analysis allowed us to calculate, for each urban system, a value of relative efficiency on the basis of which the eight networks have been ranked, distinguishing efficient from inefficient ones. The efficiency of each network is only meaningful within the context examined, in relation to the model chosen and to the sample units considered. One only needs to introduce a new network or to change the model characteristics, from input to output oriented for example, to obtain different efficient networks or different efficiency values [5]. For each urban system, with the DEA analysis, it is calculates a value of relative efficiency that has enabled us to make a ranking of the networks analyzed, distinguishing those efficient than inefficient.

\section{Definition of DEA parameters}

There have been two parallel analyses: the first one assuming the constant returns to scale using the CCR method; the second one assuming the variable returns to scale using the BCC method. Both analysis types are input oriented: the level of relative efficiency is therefore the maximum proportion of the inputs that the network must guarantee, if efficient, to have at least the current level output; it means that the necessary movement to reach the output level is attributed to the input. Within the analysis are also evaluated some cases in which efficient network cities are adopted as peer for some of the inefficient (i.e., efficient and dominant cities evaluated as a best practice, and whose input values can be used as reference by the inefficient cities and by them dominated).The inputs and outputs chosen to measure the level of performance of road systems are given in Table 1 and are subdivided according to the four macro-areas of investigation: traffic flow, accessibility, safety, public transport. Since the DEA shows, within the cases of inefficient networks, the input values that should be adopted in order to achieve efficiency, the inputs are represented by values that needs to be minimized (by contrast the output values should be maximized).For the nature of the analysis therefore, for some of the indicators

Table 1: $\quad$ Input and output used.

\begin{tabular}{|l|l|l|}
\hline \multicolumn{1}{|c|}{$\begin{array}{c}\text { Macro-areas/ } \\
\text { Input-Output }\end{array}$} & \multicolumn{1}{c|}{ Input } & \multicolumn{1}{c|}{ Output } \\
\hline Traffic flow & $\begin{array}{l}\text { (Rate of vehicles registered in the } \\
\text { metropolitan area)/(length metropolitan } \\
\text { area network -l.m.a.n.) }\end{array}$ & Level of Service \\
\hline Accessibility & $\begin{array}{l}\mathrm{n}^{\circ} \text { of major attractors within } 300 \mathrm{~m} \text { from } \\
\text { the town hall }\end{array}$ & $\begin{array}{l}\text { (Rate of average time needed to reach the } \\
\text { town hall)/(n }{ }^{\circ} \text { of main accesses) }\end{array}$ \\
\hline Safety & $\begin{array}{l}\text { (Rate of } € \text { spent by the } \\
\text { Administration)/(l.m.a.n.) }\end{array}$ & (Rate of $\mathrm{n}^{\circ}$ of fatal accidents)/(l.m.a.n.) \\
\hline $\begin{array}{l}\text { Local Public } \\
\text { Transport }\end{array}$ & (Rate of $\mathrm{n}^{\circ}$ of public buses)/(l.m.a.n) & $\begin{array}{l}\text { (Rate of } \mathrm{n}^{\circ} \text { passengers transported in a year } \\
\text { from bus system)/(l.m.a.n.) }\end{array}$ \\
\hline
\end{tabular}

chosen, is calculated the reciprocal value needed in order to keep coherence between the values of the production calculated functions. The indicators are 
evaluated according to their ease of retrieval. It is preferred to use simple and generic indicators that are easy to acquire, rather than high performance and characteristic indicators that are difficult to find.

The inputs and outputs shown in Table 1, by associating to each one an identifying code, are described in detail:

- I_1 (rate of vehicles registered in the metropolitan area)/(length metropolitan area network): although generic, it is an indicator able of showing the occupation vehicular network level. Flow density indicators are easy to find within the data base, updated annually by the websites of Italian municipalities or Public car Register;

- O_1 Level Of Service, LOS: it is an indicator of quality level and network congestion. For the purposes of analysis was used the standard value V/C specified in HCM manuals; its value increases with increase of congestion and network's low quality. It hasn't been possible to calculate the average value of the LOS for all networks and it was decided to use an identical value of 0,55 (which indicates an LOS between B and C, being the one representative of the different traffic conditions in medium-sized cities such as those studied) for all the analyzed networks. The indicator has been used in the analysis by calculating the reciprocal value $(1 / \mathrm{LOS})$, so as to minimize the effect;

- I_2 number of major attractors within $\mathbf{3 0 0} \mathbf{~ m}$ from the town hall: it is an indicator of the accessibility degree of schools, public offices, places of entertainment and culture from a given point, symbolically identified in the Town; higher the number of attractors, higher the degree of accessibility of the network, with a consequent increase in the level of satisfaction of users of the same. The data has been calculated with GIS and used in the analysis by calculating the reciprocal value (1/number attractors);

- O_2 Rate of average time needed to reach the town hall: the indicator of the degree of network's accessibility is calculated using of GIS with which have been identified the main accesses of the urban road network. The time spent along the shortest path from every access to reach the Municipality has been calculated. They have been added together then and divided by the number of accesses obtained from the network. Lower the value obtained, higher is the level of satisfaction of the user's network. The indicator was therefore used in the analysis by calculating the reciprocal value (1/(2times/2accesses $))$;

- I_3 (Rate of $€$ spent by the Administration)/(length metropolitan area network): it is an indicator of road safety; the higher its value, the higher is supposed to be the safety through the maintenance and upgrading road. Absent data from the survey on-line have been recovered through direct calls to the offices of technical competence. The indicator was used in calculating the reciprocal value (1/(spent $€ / \mathrm{km}$ network));

- O_3 (Rate of number of fatal accidents)/(length metropolitan area network): it is an indicator of road safety; the higher its value, the higher are supposed to be the inefficiencies and dangers of the road system, 
consequently the indicator was used in calculating the reciprocal value (1/(number of deaths $/ \mathrm{km}$ network));

- I_4 (Rate of number of public buses)/(length metropolitan area network): it is an indicator of the local public transport service efficiency degree; indicator of the flow density of the local public transport. The higher its value, the higher is supposed to be the degree of satisfaction of the users that can avail oneself of a fast and capillary service.

- O_4 (Rate of number of passengers transported in a year from bus systems)/(length metropolitan area network): it is an indicator of satisfaction degree of users of public service. Although it was easy to find for the provincial capitals, while for others it was necessary to contact the company bus service.

The use of DEA, moreover, requires a minimum network's number to be able to apply in order to obtain a good level of discrimination in the result of efficiency between the same. One of the good practice rules suggests that the discrimination level is at least equal to twice the product of output and input. The data rule has been respected in all tests elaborated. In Tables 2 and 3 are the elementary data and the values of input and output calculated and elaborated.

Table 2: $\quad$ Elementary data.

\begin{tabular}{|c|c|c|c|c|c|}
\hline Cities & $\begin{array}{c}\text { Metropolitan area } \\
{[\mathrm{Km}]}\end{array}$ & $\begin{array}{c}\text { Vehicles } \\
\text { registered } \\
{\left[n^{\circ}\right]}\end{array}$ & $\begin{array}{c}\text { Major } \\
\text { attract. } \\
{\left[n^{\circ}\right]}\end{array}$ & $\begin{array}{c}\text { Average time } \\
{[t]}\end{array}$ & $\begin{array}{c}\text { Main acces. } \\
{\left[\mathbf{n}^{\circ}\right]}\end{array}$ \\
\hline Benevento & 180 & 48.569 & 9 & 33,70 & 5 \\
\hline Caltanissetta & 140 & 51.211 & 5 & 21,40 & 6 \\
\hline Crotone & 280 & 43.032 & 11 & 54,10 & 5 \\
\hline Matera & 185 & 47.585 & 10 & 34,00 & 5 \\
\hline Savona & 165 & 52.981 & 13 & 31,70 & 4 \\
\hline Viareggio & 225 & 54.634 & 7 & 27,10 & 4 \\
\hline Vigevano & 175 & 47.525 & 10 & 41,40 & 6 \\
\hline Viterbo & 195 & 62.049 & 6 & 34,40 & 6 \\
\hline Cities & Euro spent [€] & $\begin{array}{c}\text { Fatal accidents } \\
{\left[\mathrm{n}^{\circ}\right]}\end{array}$ & $\begin{array}{c}\begin{array}{c}\text { Public buses } \\
{\left[\mathbf{n}^{\circ}\right]}\end{array} \\
\end{array}$ & $\begin{array}{c}\text { Pax per } 1000 \text { cit. } \\
{\left[n^{\circ}\right]}\end{array}$ & LOS \\
\hline Benevento & $3.085 .000,00$ & 2,70 & 154 & 37,80 & 0,55 \\
\hline Caltanissetta & $500.000,00$ & 9,70 & 74 & 9,70 & 0,55 \\
\hline Crotone & $3.450 .000,00$ & 9,00 & 207 & 11,40 & 0,55 \\
\hline Matera & $1.250 .000,00$ & 2,70 & 211 & 24,40 & 0,55 \\
\hline Savona & $1.300 .000,00$ & 5,30 & 221 & 72,20 & 0,55 \\
\hline Viareggio & $1.983 .000,00$ & 8,70 & 16 & 19,02 & 0,55 \\
\hline Vigevano & $670.000,00$ & 5,00 & 9 & 5,07 & 0,55 \\
\hline Viterbo & $2.159 .000,00$ & 7,30 & 135 & 42,20 & 0,55 \\
\hline
\end{tabular}

Table 3: $\quad$ Original value input.

\begin{tabular}{|l|l|l|l|r|r|r|r|r|}
\hline Cities & I_1 & I_2 & I_3 & I_4 & O_1 & O_2 & O_3 & \multicolumn{1}{c|}{ O_4 } \\
\hline Benevento & 269,83 & 0,11 & 0,00006 & 1,17 & 1,82 & 0,15 & 66,67 & $13.027,35$ \\
\hline Caltanissetta & 365,79 & 0,20 & 0,00028 & 1,89 & 1,82 & 0,28 & 14,43 & $4.175,64$ \\
\hline Crotone & 153,69 & 0,09 & 0,00008 & 1,35 & 1,82 & 0,09 & 31,11 & $2.516,06$ \\
\hline Matera & 257,22 & 0,10 & 0,00015 & 0,88 & 1,82 & 0,15 & 68,52 & $8.021,40$ \\
\hline Savona & 321,10 & 0,08 & 0,00013 & 0,75 & 1,82 & 0,13 & 31,13 & $27.371,68$ \\
\hline Viareggio & 242,82 & 0,14 & 0,00011 & 14,06 & 1,82 & 0,15 & 25,86 & $5.452,65$ \\
\hline Vigevano & 271,57 & 0,10 & 0,00026 & 19,44 & 1,82 & 0,14 & 35,00 & $1.845,48$ \\
\hline Viterbo & 318,20 & 0,17 & 0,00009 & 1,44 & 1,82 & 0,17 & 26,71 & $13.763,04$ \\
\hline
\end{tabular}


To observe the responses of different urban networks have been elaborated 10 tests divided into two groups, as shown in Table 4:

1. 1 Input $=1$ Output: for a total of four tests, one for pairs of output-input belonging to the same macroarea oriented to measure the effect of the production function for each macroarea;

2. 2 Input = 2 Output: for a total of six tests, one for every two pairs of inputoutput.

Table 4: $\quad$ Test.

\begin{tabular}{|c|c|c|c|c|c|c|c|c|c|}
\hline Group & TEST & I_1 & I_2 & I_3 & I_4 & O_1 & O_2 & O_3 & O_4 \\
\hline 1 & 1 & $\mathrm{X}$ & & & & $\mathrm{X}$ & & & \\
\hline 1 & 2 & & $\mathrm{X}$ & & & & $\mathrm{X}$ & & \\
\hline 1 & 3 & & & $\mathrm{X}$ & & & & $\mathrm{X}$ & \\
\hline 1 & 4 & & & & $\mathrm{X}$ & & & & $\mathrm{X}$ \\
\hline 2 & 5 & $\mathrm{X}$ & $\mathrm{X}$ & & & $\mathrm{X}$ & $\mathrm{X}$ & & \\
\hline 2 & 6 & $\mathrm{X}$ & & $\mathrm{X}$ & & $\mathrm{X}$ & & $\mathrm{X}$ & \\
\hline 2 & 7 & $\mathrm{X}$ & & & $\mathrm{X}$ & $\mathrm{X}$ & & & $\mathrm{X}$ \\
\hline 2 & 8 & & $\mathrm{X}$ & $\mathrm{X}$ & & & $\mathrm{X}$ & $\mathrm{X}$ & \\
\hline 2 & 9 & & $\mathrm{X}$ & & $\mathrm{X}$ & & $\mathrm{X}$ & & $\mathrm{X}$ \\
\hline 2 & 10 & & & $\mathrm{X}$ & $\mathrm{X}$ & & & $\mathrm{X}$ & $\mathrm{X}$ \\
\hline
\end{tabular}

In this paper we present the second step of the analysis with using DEA: in the first step, also divided in two groups, we used four input and one output in the group 1 and one input and four output in the group 2 [2].

The 10 tests have been developed both with CCR (constant returns to scale, hereinafter defined as CRS) method and with BCC (returns to scale variables, hereinafter referred to as VRS) method. The test results were divided into two analyses: comparisons among the efficiency results of the two test groups and details of comparisons among efficient and inefficient city.

\section{Results}

\subsection{Comparisons between the four test groups efficiency results}

Tables 5 shows the obtained results respectively in the CRS and VRS tests, belonging to the first group, in which two outputs and two inputs were used.

Table 5: $\quad$ Results CRS/VRS - Group 1.

\begin{tabular}{|l|c|c|c|c|c|c|c|c|}
\cline { 2 - 9 } \multicolumn{1}{c|}{} & \multicolumn{9}{c|}{ TEST } \\
\cline { 2 - 9 } \multicolumn{1}{c|}{} & 1_CRS & 2_CRS & 3_CRS & 4_CRS & 1_VRS & 2_VRS & 3_VRS & 4_VRS \\
\hline Benevento & 0,56 & 0,81 & 1 & 0,30 & 0,56 & 0,85 & 1 & 0,63 \\
\hline Caltanissetta & 0,42 & 0,85 & 0,04 & 0,06 & 0,42 & 1 & 0,20 & 0,39 \\
\hline Crotone & 1 & 0,61 & 0,33 & 0,05 & 1 & 0,84 & 0,71 & 0,55 \\
\hline Matera & 0,59 & 0,89 & 0,40 & 0,24 & 0,59 & 0,93 & 1 & 0,85 \\
\hline Savona & 0,47 & 1 & 0,21 & 1 & 0,47 & 1 & 0,45 & 1 \\
\hline Viareggio & 0,63 & 0,62 & 0,19 & 0,01 & 0,63 & 0,65 & 0,51 & 0,05 \\
\hline Vigevano & 0,56 & 0,88 & 0,11 & 0,002 & 0,56 & 0,91 & 0,22 & 0,03 \\
\hline Viterbo & 0,48 & 0,63 & 0,25 & 0,25 & 0,48 & 0,69 & 0,64 & 0,51 \\
\hline
\end{tabular}


This group of tests is the one which allowed us to observe the most efficient city for each macro area. Having to only one input and one output belonging to the same area as input data, the results show that:

- $\quad$ within the macroarea related to the traffic flow, the best city is Crotone;

- $\quad$ within the macroarea related to accessibility, Savona is the best city to the CRS test model, while to the VRS test model also Caltanissetta is efficient;

- within the macroarea related to security the city with the most efficient network is Benevento, if we observe the results obtained with the CRS model, while in those obtained with the VRS model Matera is also efficient;

- within the macroarea related to the public transportation network, the most efficient city is Savona.

Table 6: $\quad$ Results CRS/VRS - Group 2.

\begin{tabular}{|l|c|c|c|c|c|c|}
\cline { 2 - 7 } \multicolumn{1}{c|}{} & \multicolumn{7}{c|}{ TEST } \\
\cline { 2 - 7 } \multicolumn{1}{c|}{} & $5 \_$CRS & $6 \_$CRS & 7_CRS & 8_CRS & 9_CRS & 10_CRS \\
\hline Benevento & 0,93 & 1 & 0,88 & 1 & 0,81 & 1 \\
\hline Caltanissetta & 1 & 0,42 & 0,576245 & 0,89 & 0,87 & 0,12 \\
\hline Crotone & 1 & 1 & 1 & 0,70 & 0,61 & 0,39 \\
\hline Matera & 1 & 1 & 1 & 1 & 0,99 & 1 \\
\hline Savona & 1 & 0,58 & 1 & 1 & 1 & 1 \\
\hline Viareggio & 0,88 & 0,69 & 0,71 & 0,73 & 0,62 & 0,21 \\
\hline Vigevano & 0,97 & 0,60 & 0,56 & 0,88 & 0,88 & 0,11 \\
\hline Viterbo & 0,80 & 0,72 & 0,73 & 0,78 & 0,71 & 0,68 \\
\hline Benevento & 0,93 & 1 & 0,88 & 1 & 0,851683 & 1 \\
\hline Caltanissetta & 1 & 0,42 & 0,57 & 1 & 1 & 0,42 \\
\hline Crotone & 1 & 1 & 1 & 1 & 0,846154 & 0,82 \\
\hline Matera & 1 & 1 & 1 & 1 & 1 & 1 \\
\hline Savona & 1 & 0,58 & 1 & 1 & 1 & 1 \\
\hline Viareggio & 0,88 & 0,69 & 0,71 & 0,73 & 0,65 & 0,51 \\
\hline Vigevano & 0,97 & 0,60 & 0,56 & 0,923 & 0,91 & 0,225 \\
\hline Viterbo & 0,80 & 0,72 & 0,73 & 1 & 0,75 & 0,76 \\
\hline
\end{tabular}

Table 6 show the results obtained respectively in CRS and VRS tests of the second group, in which only one output and one input belonging to the same macro-area were used.

In this case we also observe one test, test number 9 on the CRS model, in which only one of the eight cities has an efficient network: Savona. Observing in detail the data inputs ( 2 and 4 ) and outputs (2 and 4) we notice that the city has better values than the other. This allows us to say that Savona is the city with the 
most efficient network in the macro-area related to accessibility and macronature of the public transport. This result is in line with that obtained in tests belonging to the third group.

We also notice that we obtain the same results from tests 5,6 and 7 , with either CRS or VRS model.

\subsection{Detail comparisons between efficient and inefficient cities}

The following figures 2, 3, 4 and 5, indicate the results of the two CRS and VRS analyses for each city and for all the tests. The $\mathrm{X}$ axis shows the individual tests, while $\mathrm{Y}$ axis shows the efficiency values results.

The results of Benevento and Caltanissetta, Figure 2, show that the first city is among the most efficient, while the second is efficient in fewer test. From Benevento's CRS test number 4 we notice a sharp decrease (Efficiency $=0.30$ ), belonging to the second group relative to public transport. However, if we look at the results for the same test in other cities, only Savona is efficient.

The Caltanissetta network has efficiency values equal to 1 within the CRS test only when also Savona, Matera, Crotone and Benevento are efficient. However, in test 5 (both to CRS and VRS tests) it's observed that Benevento is inefficient (albeit slightly, with a value close to unity and equal to 0.94), while Caltanissetta has an efficiency value equal to 1 . Observing the data input and output we realize that the output 2 has a double value for Caltanisetta compared to that of Benevento (while the output 1 is the same for both); so despite the input 1 and 2 are discretely lower, and therefore apparently better for Benevento, the network of Caltanissetta is efficient because it generates a higher output; remember, however, that the reciprocal value is calculated, which means that Caltanissetta is efficient because the average time of accessibility is much lower than that of Benevento.

The results of test CRS and VRS, Figure 3, for the city Matera and Crotone show that within test 1 Crotone is efficient in both tests, while Matera is generally the most efficient. Test 1 (both CRS that VRS test) is one in which only Crotone is efficient, because all the cities have the same output (LoS it is assumed to be equal to 0.55 ) while the vehicles registered per $\mathrm{km}$ in Crotone are equal to 153, 69 VS the much larger values of the other cities ranging from 242.82 (Viareggio) to 365.79 (Caltanissetta).

The CRS and VRS test results of Savona and Viareggio, respectively the more efficient city and one of the three cities with the worst results (Viterbo, Viareggio and Vigevano), shown in Figure 4, show that the network of Viareggio never reaches values efficiency equal to 1 . This means that Viareggio is never on the efficiency border. The results of the two most inefficient cities, Vigevano and Viterbo, Figure 5, show that in CRS tests neither of the two cities reaches the efficiency. Also, Viterbo achieves efficiency only in VRS test (test 8, group 2) in which six out of eight networks are found to be efficient. 

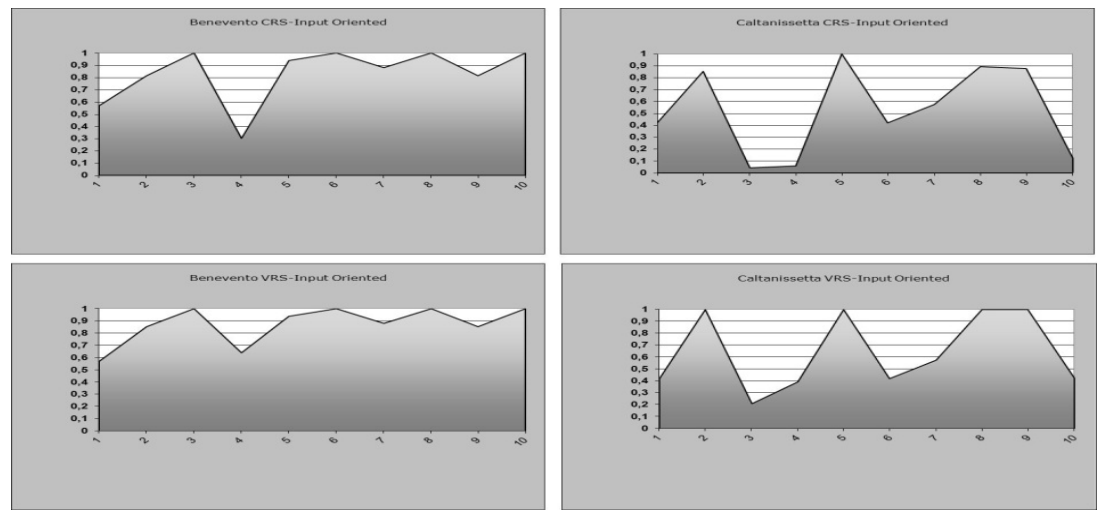

Figure 2: $\quad$ CRS/VRS test: Benevento - Caltanissetta.
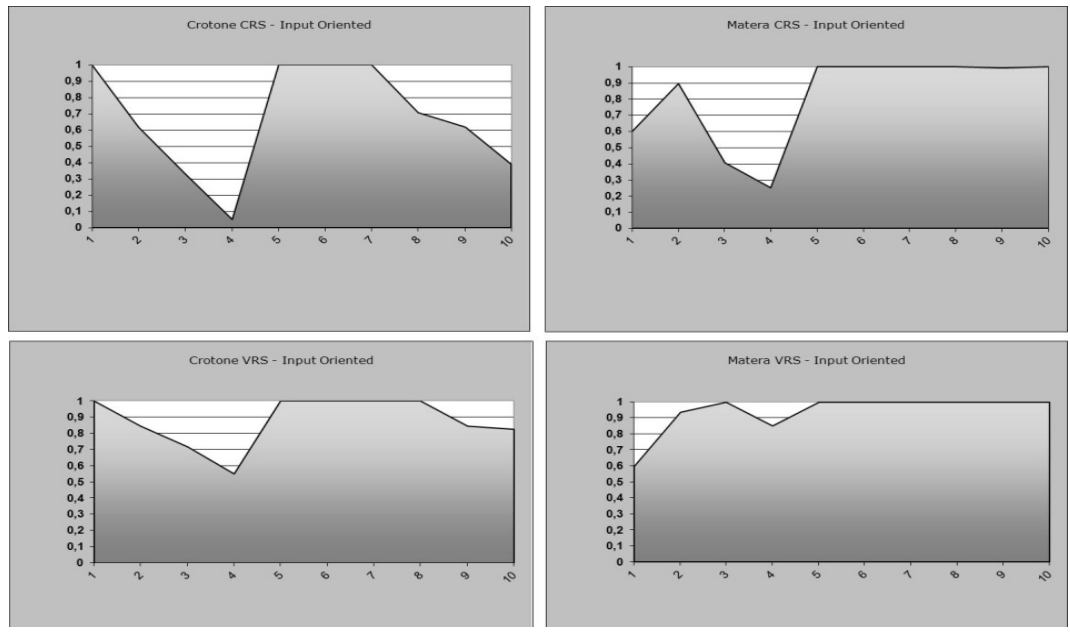

Figure 3: $\quad$ CRS/VRS test: Crotone - Matera.
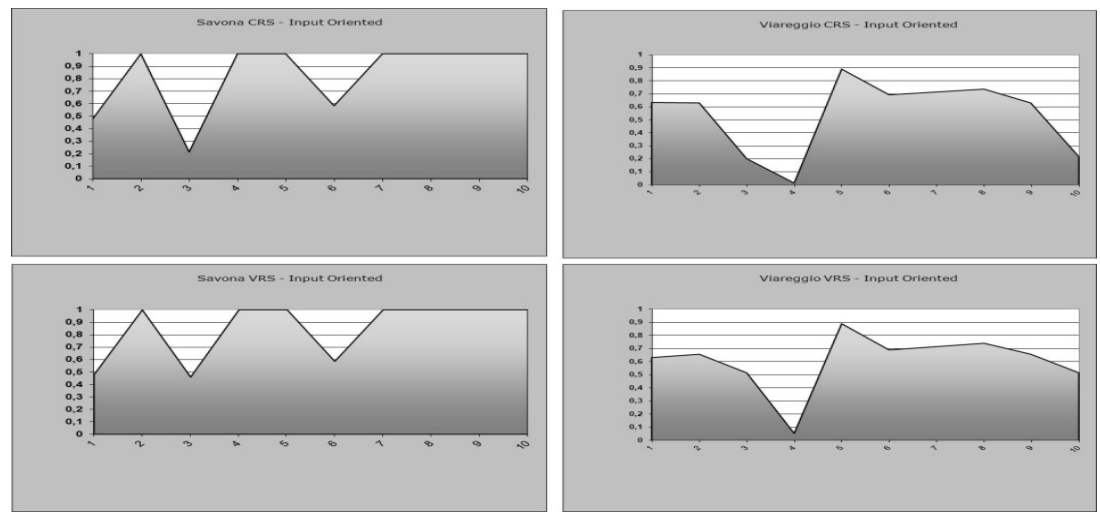

Figure 4: $\quad$ CRS/VRStest: Savona - Viareggio. 

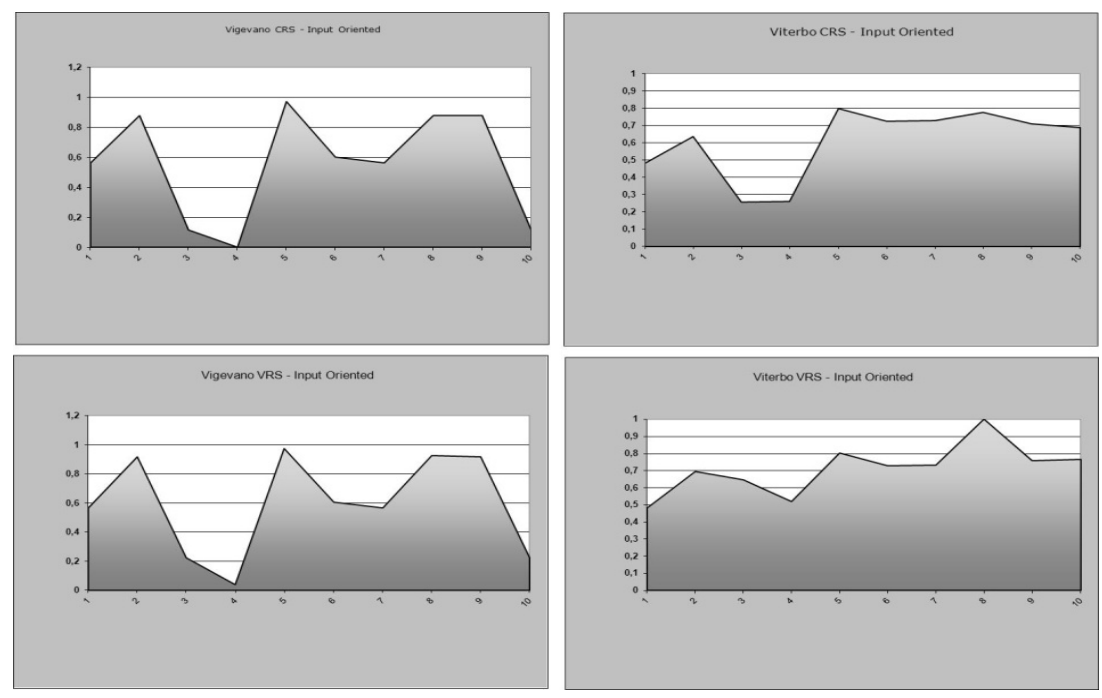

Figure 5: $\quad$ CRS/VRS test: Vigevano -Viterbo.

\section{DEA conclusions}

The cities with the most efficient road networks are Savona, Matera and Benevento. Table 7 shows the ranking of each city in two different tests: this position has been determined by counting the number of times each city was efficient (with efficiency value equaling to 1). It is specified, however, that:

- In CRS tests, Viareggio Viterbo Vigevano never reached efficiency;

- $\quad$ in VRS test, Savona and Matera were both first with the same score; also Benevento and Caltanissetta had the same score, while Viareggio and Vigevano have never reached efficiency.

Table 7: $\quad$ Ranking and Count Value of efficiency.

\begin{tabular}{|l|c|c|c|c|}
\cline { 2 - 5 } \multicolumn{1}{c|}{} & \multicolumn{2}{c|}{ Ranking } & \multicolumn{2}{c|}{ Count value of efficiency equal to 1 } \\
\cline { 2 - 5 } \multicolumn{1}{c|}{} & CRS & VRS & CRS & VRS \\
\hline Savona & 1 & 1 & 7 & 7 \\
\hline Matera & 2 & 2 & 5 & 5 \\
\hline Crotone & 3 & 3 & 4 & 4 \\
\hline Benevento & 4 & 4 & 4 & 4 \\
\hline Caltanissetta & 5 & 5 & 1 & 0 \\
\hline Viterbo & 6 & 6 & 0 & 0 \\
\hline Viareggio & 7 & 7 & 0 & 0 \\
\hline Vigevano & 8 & 8 & 0 & \\
\hline
\end{tabular}

The CRS test shows to be more restrictive than the VRS test. Anyhow the three cities with primacy maintained it in both the CRS and VRS test.

The efficiency degree achieved by each network is meaningful only in the context in which it has been measured, and then only in relation to the specific 
model and sample units considered. Simply introducing a new road network or changing the model characteristics (from input to output-oriented) or inputs, will produce different efficient networks or different efficiency values [6].

The first group test are those who made it possible to highlight which of the eight cities are more powerful compared to the specific macro-area, in fact discriminating against the others, but at the same time allowing we to have an immediate understanding of the macro-area strength of each cities studied. The second group show the most efficient network by using input and output of the macro-areas analyzed in pairs; they also show that if a city has a network with highly competitive values compared to the other cities, these values arise if are compared both single outputs and inputs data, or pairs of them.

The results show that the DEA technique is well suited for analyzing and comparing road networks. The main issue is not that much the technique as the calculation of the indicators, which should be chosen according to their utility and on the basis of their ability to retrieve the data necessary for processing them.

\section{Acknowledgement}

This work forms part supported by grant of a research project, PRIN-2009 prot. 2009EP3S42_003, in which the University di Cagliari is a partner with a research team comprising the authors of this paper, and which concerns performance assessment of road networks [2].

\section{References}

[1] Farrel, M.J., The measurement of productive efficiency, Journal of Royal Statistics Society, Series A120, 253-281, 1957.

[2] Fancello, G., Uccheddu, B., Fadda, P., The performance of an urban road system: an innovative approach using D.E.A. (Data Envelopment Analysis, SIDT Scientific Seminar, Padova, 2012.

[3] Cooper, W.W., Lewin, L.M. Seiford, Data Envelopment Analysis: Theory, Methodology and Applications, Kluwer Academic Publishers, 1994.

[4] Charnes, A., Cooper, W.W., Rhodes E., Measuring the efficiency of decision making units, European Journal of Operational Research, 429-444, 1978.

[5] Zhao, Y., Triantis, K., Murray-Tuite, P., Edera P., Performance measurement of a transportation network with a downtown space reservation system: A network-DEA approach, Transportation Research Part E 47 1140-1159, 2011.

[6] Banker, R.D., Charnes, A., Cooper, W.W., Some models for estimating technical and scale inefficiencies in Data Envelopment Analysis, Management Science, 30, 1078-1092, 1984. 